\title{
Three Sides Billboard Wind-Solar Hybrid System Design
}

\author{
Xuefeng BAI ${ }^{1, a}$, Yongjian MA ${ }^{1, a}$, Pei $\mathrm{LI}^{1 \mathrm{~b}}$ \\ ${ }^{1}$ Beijing Information Science and Technology University, Beijing, China \\ ${ }^{a}$ School of Automation $\quad{ }^{b}$ Mechanical and electrical training center
}

\begin{abstract}
With the high development of world economy, the demand of energy is increasing all the time, As energy shortage and environment problem are increasing outstanding, Renewable energy has been attracting more and more attention. A kind of three sides billboard supply by wind-Solar hybrid system has been designed in this paper, the overall structure of the system, components, working principle and control strategy has been analyzed from the system perspective. The software and hardware of the system are debugged together and the result is acquired. System function is better and has achieved the expected results.
\end{abstract}

\section{IINTRODUCTION}

With the high development of world economy, the demand of energy is increasing all the time, As energy shortage and environment problem are increasing outstanding, energy saving and environment protection become a hot spot of the scientific and technological development. Renewable energy has been attracting more and more attention.

As a representative of the renewable energy, The wind generation, photovoltaic generation are the two main renewable energy utilization methods and are under the fast development.[1] But they have their own advantages and disadvantages. Integrating the advantages of wind energy and solar energy, Using the complementary advantages and power conversion structure similarity of power generation system, adding reasonable control technology, can make up for the inadequacy of wind energy and solar power respectively. Wind-solar complementary provides a more reliable performance to realize the green renewable energy power generation system with energy storage function and improve the power output characteristic of system.[2]

Urban road along the advertising is not only a means of advertising industry development of a kind of media, but an important component part of modern city environment construction and layout. Three sides billboard have the advantages that same area can be three times the performance of the space and of visual perception, widely used in urban road advertising.

Based on the sufficient research on structure, the principle and using occasions of three sides billboard on the market, three sides billboard which can meet the use requirements and has its own characteristics have been designed and made, Specially wind-solar hybrid system according with using characteristics of three sides billboard have been designed.

\section{The System Design}

Wind-solar hybrid system structure diagram of three sides billboard is shown in figure1.it is mainly composed of solar arrays, wind turbines, wind-solar hybrid controller, storage battery, inverter, billboard lighting LED lights, 
etc.

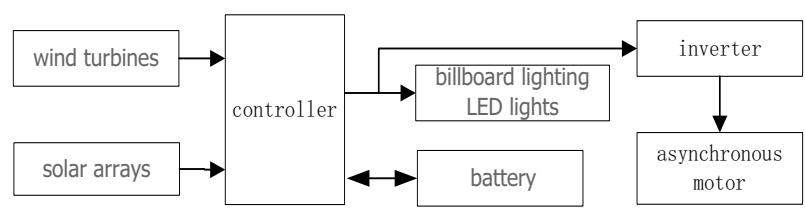

Fig. 1 wind-solar hybrid system structure diagram of three sides billboard

\section{Controller Design}

Controller is the main part of the whole wind-solar hybrid system, unstable alternating current (ac) output of wind generator and unstable DC output of photovoltaic array are converted to a stable DC output to battery and load by the controller, and also control working pattern and the way of charging and discharging of the battery. [3-4]

\subsection{Wind-solar hybrid system controller structure}

Controller hardware main part is composed of power circuit and digital control circuit. Power circuit is mainly composed of wind power circuit, solar power circuit and load control circuit. Controlled by digital control circuit with a single-chip microcomputer as the core of power circuit and carried out in accordance with the control strategy of power transformation. Controller hardware structure is shown in the middle of the dashed line frame part in Fig. 2

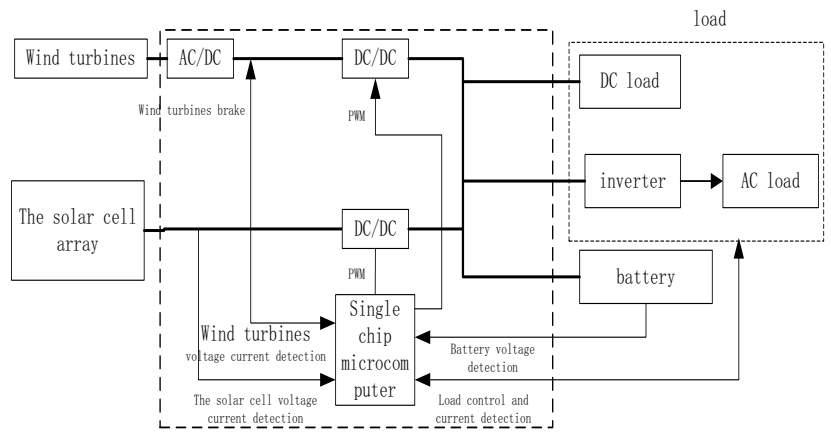

Fig.2 Controller hardware structure

\subsection{The system controller software design}

The main program: the main program mainly includes each functional module initialization and the subroutine call . Initialized each functional module of the system included the system clock, AD conversion module, I/O interface, PWM module and interrupt vector initialization.
Subroutines include charging management subroutine, power supply management subroutine and display subroutine. Software design flow chart is shown in Fig. 3.

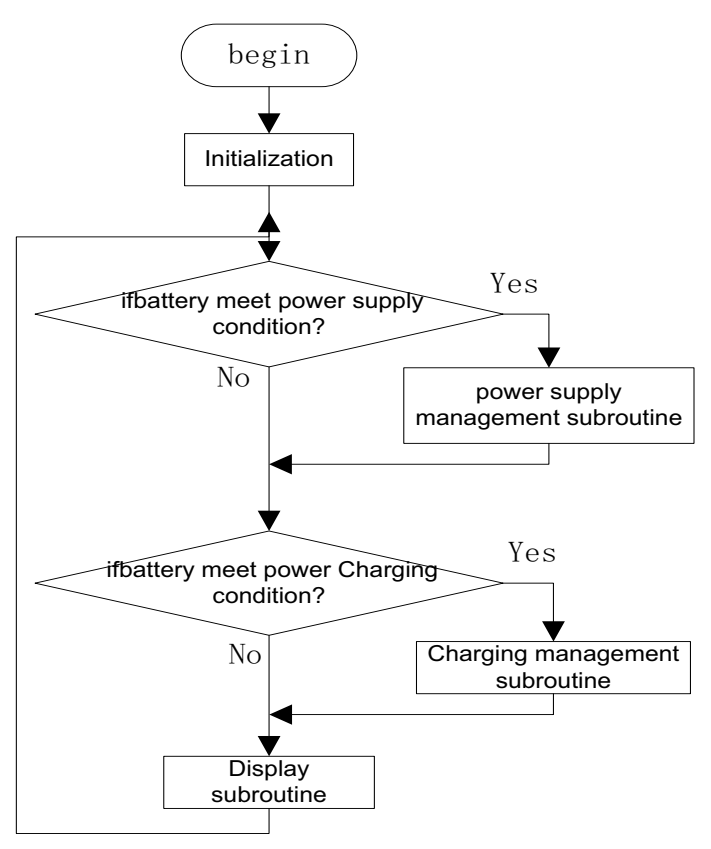

Fig. 3 main program flow chart4

\section{The Inverter Design}

\subsection{The structure of the inverter}

The dashed part in Fig.4 is the general structure diagram of inverter. Inverter is mainly composed of four parts: DC/DC booster circuit, DC/AC inverter circuit, PWM drive circuit and SPWM driver circuit.[5]

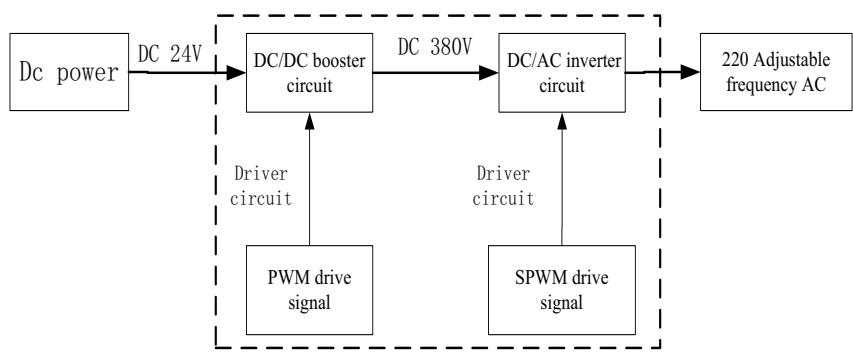

Fig. 4 The inverter general structure diagram

\subsection{The inverter circuit design}

Sine wave inverter circuit principle diagram is shown in figure 5.Main circuit includes the push-pull booster circuit, high frequency step-up transformer, single-phase bridge rectifier circuit, inverter circuit, LC filter circuit. 
The working process of the inverter circuit: DC $24 \mathrm{~V}$ battery produced by Battery is turned to high frequency rectangular wave through push-pull inverter circuit, to high voltage high frequency rectangular wave through high frequency step-up transformerB1, to DC380 through high-frequency rectifier filter circuit. Through the single-phase bridge inverter circuit to obtain frequency adjustable SPWM wave, Finally, SPWM wave is converted into frequency adjustable 220 alternating current by LC filter circuit. Because three sides billboard is powered by $220 \mathrm{AC}$ gear motor, so that according to the requirements of three sides turn over billboards to adjust the frequency of $220 \mathrm{AC}$, thus speed of three billboards inversion is adjusted better to achieve the best effect. DC/DC booster control signal is provided by PWM signal produced by circuit that SG3525 chip is as the center and DC/AC inverter circuit control signal is provided by SPWM signal generated by the integrated SPWM wave circuit board.

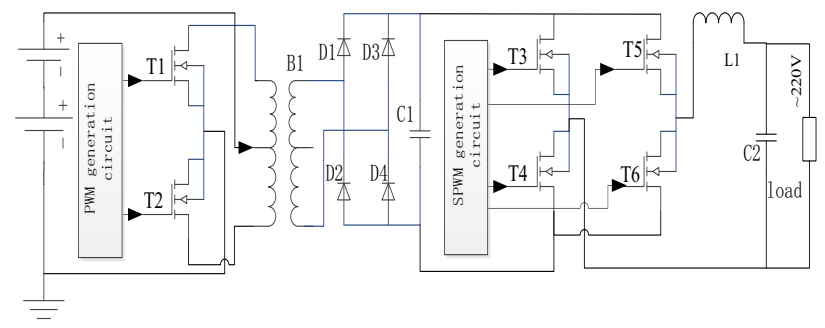

Fig 5 Sine wave inverter circuit principle diagram

\subsection{The inverter and three sides billboard debugging}

Connecting three signs point power plug to the output of the inverter and the inverter input to the $24 \mathrm{~V}$ battery, three sides bill board can work normally. By changing the inverter output frequency, three triangular prism rotating speed of billboards will be adjusted the effects showed in figure 6 .

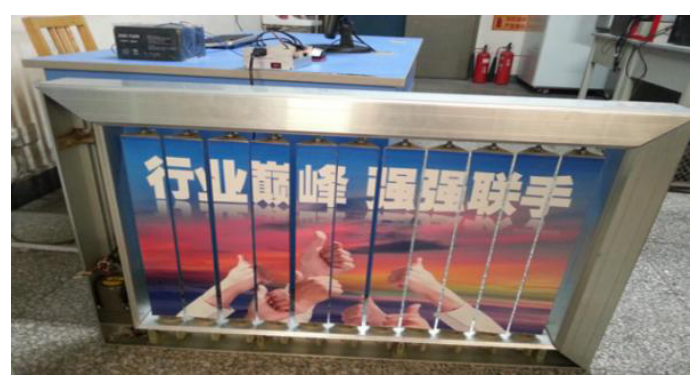

Fig. 6 The inverter and three billboards debugging effect

\section{Conclusion}

Based on the summary of wind-solar hybrid system development status of domestic and foreign markets, technology and the characteristics of the three sides billboard, A kind of three sides billboard supply by wind-solar hybrid system has been designed, the overall structure of the system, components, working principle and control strategy has been analyzed from the system perspective. Off-grid type wind-solar hybrid system controller and idea of single-phase bridge inverter required by three advertising system are put forward, the principle diagram of the hardware circuit and software design flow diagram are designed, the inverter of the rectifier circuit, inverter circuit, drive circuit and protect circuit design features are analyzed, the controller and inverter have been made, respectively, the controller and the inverter debugging have been completed, Ultimately, the software and hardware of the system are debugged together and the result is acquired. System function is better and has achieved the expected results, The experimental results show that the billboard installed to the city road or highway, in addition to advertising effectiveness, but also energy conservation and environmental protection, beautify the environment.

\section{Acknowledgement}

This work has been supported in part by Beijing municipal education commission science and technology project (No.KM201511232023); City Board Education teaching-undergraduate research training program(national level)Beijing Information Science and Technology University 2015 college students' scientific and technological innovation projects(No.94 The ocean wave generate electricity device design).

\section{References}

1. Menghui WANG, Jencheng YANG, XiuHong LI. Application of Extension Method to Selecting of Solar Power Systems[J].Department of Electrical Engineering, 2010: 160-163. 


\section{MATEC Web of Conferences}

2. YaaiCHEN,Yongao JIN. Review of control technologies for wind-solar Hybrid Generation system [J]. Electric Drive, 2012(42):3-9

3. Wei ZHOU, Hongxing YANG, Zhaohong FANG. Battery Behavior Rediction and Battery Working States Analysis of a Hybrid Solar-wind Power Generation System [J]. Renewable Energy, 2008, 33(6): 1413-1423.

4. Pablo Valera, Antonio Esteban, Maria de los Reyes Carrillo. Solar energy: comparative analysis of solar technologies for electricity production [J].2003, (18):2482-2485.

5. Yongjian LI, Dawei YUE, Hongxun LIU. Wind-solar Complementary Power Inverter Based on Intelligent Control[C] 2009 4th IEEE Conference on Industrial Electronics and Applications,Xi'an,2009:3635-3638. 